https://doi.org/10.21670/ref.1802002

Articles

\title{
Possibilities of Mexican SMEs Insertion in the Aerospace Industry Value Chain, the Baja California Case
}

\section{Posibilidades de inserción de pymes mexicanas en la cadena de valor de la industria aeroespacial, el caso de Baja California}

\author{
Juana Hernández Chavarria a* (iD https://orcid.org/0000-0003-0268-6280 \\ Jorge Carrillob $^{\text {(DD }}$ https://orcid.org/0000-0002-8533-2797
}

Received on November 10, 2016.

Accepted on September 22, 2017.

${ }^{*}$ Corresponding author: Juana Hernández Chavarria e-mail: hernandez.juanny6@gmail.com

This work is licensed under a Creative Commons Attribution-NonCommercial 4.0 International License.

${ }^{a}$ Facultad Latinoamericana de Ciencias Sociales, Mexico, e-mail: her
${ }^{\mathrm{b}}$ El Colegio de la Frontera Norte, Mexico, e-mail: carrillo@colef.mx

\section{Abstract}

The goal of this article is to analyze the aerospace industry in Baja California, Mexico. The methodology is based on the application of an electronic questionnaire and face-to-face in depth interviews. Our results shows that the insertion of companies has been conditioned by several factors: the basic certification is only the first step; the real challenge is to find niches of opportunity and bargaining power to achieve a productive contract, which demands entrepreneurial, legal and economic skills. This analysis is a pioneer in the study of Mexican companies participating in this emerging sector. The main limitations were the access to the companies' information and the rejection to participate in the study. The main finding is there are very few Mexican suppliers integrated to the global value aerospace chain but if the trend of growth is maintained, it may had greater integration in the near future, and possibly a greater economic spill and technology transfer.

Keywords: aerospace industry, smes, foreign direct investment, Baja California, value chain.

\section{Resumen}

El objetivo de este trabajo es analizar a las empresas de la industria aeronáutica en Baja California. La forma de aproximación a los resultados fue por medio de un cuestionario electrónico y entrevistas a profundidad. Los resultados muestran que la inserción de empresas ha estado condicionada por diversos factores, la certificación básica es solo el primer paso; el verdadero reto es encontrar nichos de oportunidad y

CITATION: Hernández, J. y Carrillo, J. (2018). Possibilities of Mexican SMEs Insertion in the Aerospace Industry Value Chain, the Baja California Case [Posibilidades de inserción de pymes mexicanas en la cadena de valor de la industria aeroespacial, el caso de Baja California]. Estudios Fronterizos, 19, e002, doi:10.21670/ref.1802002 
capacidad de negociación para lograr contratos productivos, lo cual demanda habilidades empresariales, jurídicas y económicas. Este trabajo es pionero en el estudio de empresas mexicanas participantes en este sector emergente. La principal limitación fue el acceso a la información sobre las empresas y que accedieran a participar en este estudio; mientras que como hallazgo encontramos que muy pocas empresas son proveedores, pero si se mantiene una tendencia de crecimiento, se puede tener mayor integración en un futuro cercano, y eventualmente una mayor derrama económica y transferencia tecnológica.

Palabras clave: industria aeroespacial, pymes, inversión extranjera directa, Baja California, cadena de valor.

\section{Introduction ${ }^{1}$}

Foreign Direct Investment (FDI) in Mexico has focused on a select number of states, which may be due to agglomeration economies in a regional level mainly in Border States. In the aeronautics case, it also obeys the industry's distinctive trends, such as higher levels of decentralization activities in different parts of the world, due to changes towards outsourced processes rather than the centralized ones. This offers opportunities for emerging countries such as Mexico, by taking advantage of the productive capacities and the industrial tradition of the regions.

The state of Baja California holds natural, material and human resources that have made feasible the arrival of foreign companies, not only in aerospace, but also in sectors such as electronics and food, because it offers advantages for the installation of multinational companies in terms of skilled workers with extensive experience in maquila, strategic location with the United States, the benefits of the North America Free Trade Agreement (NAFTA), and technological infrastructure work, which opens new opportunities for local industry.

However, there is few data so far on the inclusion of local businesses, even though the state's government has granted specialty niches to boost the aeronautics sector such as: supplier certifications, advanced technical capabilities and advanced materials. But they also recognize the existence of weaknesses in the region such as a weak supply chain, insufficient response to the global technological trends, and low incorporation of cutting-edge technology. Therefore, this study aims to provide information about companies from Baja California participating in the aeronautics industry, the questions are set to three directions: 1) what are the characteristics of Mexican aerospace companies in the state of Baja California?, 2) to which links in the global production chain are they attached? And 3) what activities do they carry out and what are the opportunities to continue diversifying activities?

This assignment is divided into six parts; the first one is a brief description of the particular characteristics of the aeronautics sector on a productive and organizational level. The second one features the rationality of mobility of production in this sector and how's the impact of investment in countries with no background in the industry as it is the case of Mexico. The third one describes the aeronautics industry in the state of Baja California, after that in the fourth; the methodology used to collect the information is

\footnotetext{
${ }^{1}$ This publication was made under a post-doc scholarship at UNAM.
} 
shown. The fifth part shows the results of the characteristics, links, activity and opportunities of this sector in Baja California. Finally, the general conclusions are provided in the sixth part.

\section{Discussion About the Complexity and Peculiarities of the Aeronautics Sector}

The aeronautics ${ }^{2}$ industry has features such as large investments and long production cycles where the high level of technology in the design and manufacture marks its idiosyncrasy. The complexity of the productive system and the multiplicity of disciplines that have interference in the production, define a decentralized management of the production which is dominated by large assemblers operating at an international level (Casalet, 2013).

This sector is characterized by a widely complex production process with a heavy reliance on innovation and research and development (R\&D) activities, along with a pyramidal structure dominated by original equipment manufacturer (oEM) leading enterprises, which controls the design of the final product, and delegates providers with the modules' evolution for the remaining of the production process (Eliasson, 2010; Niosi \& Zhegu, 2005). Currently, the value chain of aerospace industry relies on two main pillars: on one hand the decentralization of the productive activities and R\&D throughout the value chain; and secondly by intensifying risk-sharing partnerships between systems integrators and their main suppliers (Morissette, Barré, Lévesque, Solar-Pelletier, 2013). OEMs today focus more on design (research for greater efficiency and new materials) and sales (competition to increasingly cover more global markets) and on a lesser proportion to the production process, which, increasingly to a greater extent, it is delegated to first-tier suppliers, also called Tier 1.

\section{Aeronautics Industry Characteristics}

The aeronautics sector is part of the paradigm of advanced manufacturing, it's responsible for the design, development, manufacture, assembly, marketing, repair and sale of aircraft. The product cycle consists in the development of $\mathrm{R} \& \mathrm{D}$, design, manufacture, assembly, testing and certification, and finally, maintenance activities (López, Elola, Valdaliso \& Aranguren, 2012). Some specific traits of this industry are:

- High scientific and technological intensity.

- Programs with high cost and risk.

- Lengthy development cycles and lengthy return on investment.

- Production in short series and with high added value.

- International collaboration in design and development.

- Relevant role of the Government as a driver, customer, market regulator and defender.

${ }^{2}$ For the purpose of this paper, the aerospace and aeronautics industries will be interchangeably referred to, as synonyms. 
- Strong entry barriers.

- Critical importance of quality and safety.

- Very long life cycles, and relations between civil and military industry (Casalet, 2013; López et al., 2012).

The aeronautics industry has worldwide activities and is closely linked to global value chains with a small number of large OEM companies with a high degree of specialization, which act as final demanders to the worldwide performed activities. In this industry, a low volume, and at the same time, a high mixture of products dominates, plus the production rates are slow with a high degree of planning, engineering and quality control (Gomis \& Carrillo, 2016).

\section{Worldwide Production Structure of the Aeronautics Industry}

Worldwide, the global value chain of this industry is dominated by four large companies with a high degree of specialization which dominate the commercial and civil aircraft production market: European Aeronautic Defence and Space Company (EADS/Airbus) of European origin, Boeing (for large aircraft) from the United States, Embraer from Brazil and Bombardier from Canada, for medium aircraft; and three major engine manufacturers: General Electric, Rolls-Royce and Pratt \& Whitney (López et al., 2012; Niosi \& Zhegu, 2005).

Globally, the weight of the aeronautics industry is about $1 \%$ of the GDP; in the United States (US), is very close to that figure and in the European Union (EU) is close to $1.2 \%$. In aircraft construction, the activity intended to the civilian market is predominant, although in the us the aeronautics industry is relatively concentrated, because part of the aircraft components from large companies (from other countries) are of us origin.

The Eu concentrates more than one-third of the worldwide production; the rest is divided in three countries that manage between $2 \%$ and $5 \%$, these are: Canada, Japan and Brazil. After these, we can find Southeast Asia, with a growing presence in India and China, and Russia that has regained relevance (López et al., 2012).

Because of subcontracting policies, the concentration of the assembly activity is performed in specific cities like Montreal and Belfast for Bombardier, Seattle for Boeing, Hamburg and Toulouse for Airbus and finally Sao Paulo for Embraer (Elola, Valdaliso \& López, 2013).

The location of this industry in clusters is determined by centrifugal forces, i.e., outside the consortia, large integrators or oEMs operate so industries can be established in an area that becomes strategic in the global market. And by centripetal forces moved by public administrations and strong local first class integrators, which allow international aeronautics companies to be established in their area and also physical and technologically close sector smes; both forces seek the highest level of activity in research and innovation.

The centripetal forces cause a tractor effect from certain areas, these forces are, for example, the existence of qualified human capital in the activities that will be developed within the broad spectrum of this industry or, otherwise, the tradition in aeronautics or a similar activity, or a business network willing to setup a high-risk and long term investment (Casalet, 2013; López et al., 2012, p. 35; Niosi \& Zhegu, 2005; Office of Aerospace and Automotive Industries International Trade Administration, 2007). 
OEMs perform the final assembly of airplanes or helicopters, the manufacture of some parts and components, the design and development of new aircraft models, and the sale to the end customer.

First-tier suppliers (Tier 1): are second in importance (after OEMs) and are involved in assembly, manufacturing products with high added value and integration of major subsystems (AeroStrategy, 2009).

Second-tier suppliers (Tier 2): are companies specialized in various assemblies and sub-assemblies sections to integrate into aerostructures, avionics, engines, aircraft interiors and landing gear (Secretaría de Economía, 2012).

Third-tier suppliers (Tier 3): are small companies specialized in the design or manufacture of parts and elemental components such as screws, glass, seat covers, etc.

Finally, in the production chain of this industry we have the Engineering and design providers, as well as low cost providers specialized in the production of certain components and specific processes.

This production chain takes place in an international, rather than local, demand, and aeronautics products are made with the participation of companies throughout the world, not within a given cluster.

Another feature is the constant flow of knowledge within the entire production chain at an international level. Tacit knowledge is very important in production, some activities are defined by the skills of the worker and production standards are only achieved with experience. Codified knowledge also plays a central role and results in standards, specifications, procedures, protocols and requirements, both types of knowledge are moving in a very hierarchical protocol determined by oEMs (Hernández, 2010).

The manufacturing process involves all the activities performed before beginning the assembling of an aircraft, there is a complex process in which it is verified that the thousands of pieces that form the aircraft meet the established specifications.

Once the above aspects are reviewed by the oEms, the integration of the production chain is next, i.e., the distribution of activities among different providers that make up the value chain.

\section{Market Size Perspectives}

Worldwide sales in the aeronautics sector have been increasing since 2004 as an outcome of the demand for new aircraft and the emergence of new airlines referred to as low-cost; as well as an increase in the number of orders for the renewal of aircraft fleet from Asian countries, especially China. In addition, countries like India are increasing domestic demand for aircraft and creating a strategy to migrate the investment and stimulus from the defense aircraft industry to the commercial aircraft industry (Mani, 2010).

Sales in the sector accounted for $\$ 450$ billion dollars, the United States is the country with the highest income in the aviation industry with $\$ 204$ billion dollars, 45.3\% of the total, then France, United Kingdom and Germany are the main partners of the Airbus ${ }^{3}$ Company. Subsequently, Canada ranks in fifth place with a revenue of $\$ 22$ billion dollars; Brazil is in 10th place. It is important to note that the major aircraft

\footnotetext{
${ }^{3}$ Main company in Europe within the Aerospace Industry.
} 
and engines manufacturers in the world come from these countries, Mexico ranks15th worldwide (AeroStrategy, 2009).

The aeronautics industry can be divided into four market segments: $a$ ) the manufacture of larger capacity aircraft (also named commercial aircraft), $b$ ) the manufacture of smaller capacity aircraft (aircraft sector), c) general aviation aircraft (business aircraft) and helicopters and $d$ ) the portion of maintenance, repair and overhaul (MRO), which can be used in both civil and military. The Mro service activities involve inspection, cleaning, lubrication and replacement or repair of minor parts of the plane.

Some Mro activities are limited to the inspection, cleaning and periodic lubrication (after a certain number of flights). The specific case of repair covers the process of mechanical, for serious failures discovered during maintenance, major maintenance activities (overhaul) are also performed, which consists in a complete aircraft inspection and is performed after it has completed between 4000 and 5000 flight hours.

\section{Regulations and Certifications for the Sector}

Regulations and certifications is a central issue in this industry, due to its complexity and mode of operation, safety is the factor that governs all activities related to the final product because unlike other transportation industries, a fault in the operation of an aircraft, however small it may be, can derivate in fatal consequences (Secretaría de Economía, 2012).

Therefore, it is required to ensure its operation by the assembly and manufacture of parts and systems, and as well as the use of materials and processes that meet stricter safety and quality standards, therefore the companies performing these activities should be certified by the regulating aeronautical authorities, by certification bodies or through the company for which they are suppliers.

The globally accepted standard for the aeronautics industry is the 9100 Series and its implementation is of great importance for companies wishing to become suppliers of aircraft parts and components.

As9100 contains the requirements of Iso 9001: 2000, with the addition of 80 other critical requirements for quality in the aerospace industry, some of them are: the first inspection of the item, handling the variation of the essential characteristics, control design and development and management of suppliers.

In the case of Mexico on the issue of regulations and certifications, the Secretariat of Communications and Transportation, through the Directorate General of Civil Aeronautics (knoen in Spanish as DGAC), is the Mexican agency responsible for granting the permits that allow the establishment of aircraft, engine, parts and component factories, as well as to regulate and monitor them.

Given the complexity of the issue of certifications, the Mexican government took actions to join to the Bilateral Aviation Safety Agreement (BASA), this agreement is aimed at a mutual recognition between the authorities of Mexican and North American civil aviation (it also includes Canada) in terms of certification of parts and aerospace components according to international standards that promote aviation safety and environmental quality. In the United States, the authority responsible for this certification is the Federal Aviation Administration (FAA), while the DGAC, under the Secretariat of Communications and Transportation, is responsible on the 
Mexican side (Federación Mexicana de la Industria Aeroespacial, 2012; Secretaría de Economía, 2012).

The aeronautics industry in Mexico is constantly growing, there are about 300 companies that belong to the aerospace industry, distributed in different states. The reasons explaining the increased activity of the aeronautics industry are the advantages in terms of geographical location, its proximity to the largest market (United States), which involves reducing production costs mainly from companies operating in Europe.

The experience and level of competitiveness achieved in other sectors such as the automotive and electronics in Mexico, allows for a base of staff and companies that can be targeted towards the aeronautical sector and free trade agreements that allow preferential access in 43 markets (Secretaría de Economía, 2012).

\section{Mobility Strategies of the Transnational Aeronautics Companies}

Currently, the drivers for mobility in the aeronautics business go beyond production costs; large companies are seeking opportunities niches in areas such as engineering, or information access on R\&D in different regions of world.

Due to market growth, oEms and Tier 1 companies need to create better designs in shorter cycles, so they look for talent and capabilities worldwide, therefore some productive investments have relocated to countries like Russia, India and the United States, where engineering and design jobs have been transferred to (AeroStrategy, 2009).

The aeronautics industry is changing from processes that once were integrated to subcontracts, which imply that for each component of the aircraft; more efficient production place should to be provided, giving emerging countries great opportunities for development.

It is important to note that in this industry, not only the drivers of the traditional productive mobility are taken into account, they are also combined with new drivers, which determine the strategies of transnational corporations and move throughout the production chain; and hence the industry moves to developed or developing countries such as Mexico.

Sometimes, the companies in this industry are looking for a combination of factors (traditional or new) that drive mobility, this way, access to skilled low-cost labor can be taken into account, and also economies of scale, geographical position, currency exchange rate, and government support of the host country, depending on the activity they want to relocate. Some drivers of mobility of production of the aeronautics industry are: access to new markets, conditions of the global environment, access to cutting-edge technology and complementary incentives and conditions offered by the host country, access to labor from an advanced subcontracting industry and the type of productive activities transferred.

In the case of Mexico, there are studies that using location models, with a conditional logit model, have identified regional characteristics that influence the choice of where a manufacturing FDI was established in the second half of the 1990s, after the creation of NAFTA.

One of the main findings of the study is that FDIs in manufacturing have focused on a select group of states within the Mexican territory, suggesting that foreign-owned companies prefer a location with presence of agglomeration economies in a regional level. The Border States have become the most important region for FDIs (Jordaan, 2012). 
Currently, the international production of transnational companies has grown and has taken on new models, major changes in the global economic scenario can be observed, which makes further explanations about the FDI drivers appear, or that existing ones are modified and in some cases are replaced. Other drivers that explain the investment decisions of transnational companies are: $a$ ) a trend towards the increasing importance of technology-driven FDI (Amighini, Rabellotti, Pavia \& Scalera, 2013); $b$ ) the location of the different stages of the value chain, according to the activities of the chain link, it's decided where to move some part of the production, regardless of traditional factors such as the costs of labor; $c$ ) local socio-institutional factors, for example, currency exchange rate, political risks, regulations and policies of supranational institutions and cultural differences between countries; $d$ ) the operation of the national innovation system that offers new location advantages for multinational companies and supports the achievement of innovation within the country or region of the investment destination. Changes in the behavior of investment from multinational companies reflect the changing landscape of innovation and increasingly global supply of science and technology and innovation capacities (Organization for Economic Cooperation and Development [oEcD], 2011).

On a regional level, local public policies, government incentives and the quality of infrastructure, impact location decisions for $\mathrm{R} \& \mathrm{D}$ in a particular region. The efforts of regional or national innovation can open up new windows of opportunity for attracting FDIs, since greater investment in R\&D will attract multinational companies focused on activities beyond manufacturing, the most sophisticated investments are attracted by an innovative local context.

\section{The Aeronautics Industry in the State of Baja California}

On the 2014 agenda of innovation of the state of Baja California, the aerospace sector is defined as one of the state's areas of expertise. Mexicali is the city where it is promoted as a productive vocation. The Secretariat of Economy through the National Institute of the Entrepreneur (Inadem), also identified seven key sectors for Baja California, including the aerospace industry, based on the quality of jobs, the jobs created, the Total Census Value Added (vacB in Spanish), the sector's output and remuneration (Consejo Nacional de Ciencia y Tecnología [Conacyt], 2014, p. 24).

The origins of the aerospace industry in Baja California occurred in 1927 with the founding of the Compañía Aérea de Construcción y Transporte S.A. (Construction and Transportation Air Company) in the municipality of Tijuana. However, the development of the sector in the region did not start until 1966 with the establishment of Rockwell and Switch Luz enterprises. Today, according to a study by Gomis \& Carrillo (2016), based on ProMéxico data, 106 companies operate in the state, heterogeneously distributed, $85.3 \%$ are concentrated in Tijuana and Mexicali. These companies are engaged in manufacturing and assembly of electrical and electronic parts for aircraft and engine equipment.

The state of Baja California has developed various mechanisms to boost the aerospace sector, the most notable project Bilateral Aviation Agreement Safery (BASA). This bilateral agreement with the us allows the certification of components and aerospace designs, after meeting the standards and requirements of the FAA. 
It also has a cluster association where established companies are bonding together with the objective of identifying opportunities and constraints that allow for further development of the aerospace sector in the region (Conacyt, 2014).

The entity as such, specializes in activities of precision machining, electrical systems and power, hydraulic and interiors systems and processes shaping metal plates and in some cases special processes, thermal and surface treatments and maintenance activities and motor components repair (ProMéxico cited in Conacyt, 2014).

The companies identified in this region are of foreign capital and there is no official data from local companies, the most noteworthy foreign companies include: Aerodesing de México, Delphi Connections Systems, Eaton Aerospace, and Honeywell Aerospace de México, to name a few. Half of the companies in this sector are located in Tijuana, a third in Mexicali and the rest in Tecate, Ensenada and Rosarito. Medium and large companies are located in Tijuana and Mexicali, and small and micro companies in Tecate and Ensenada (Conacyt, 2014, p. 59).

Most state enterprises are Tier 2, their activity involves assembly of components and manufacturing of parts, they are large maquila companies, with an intensive employment generation, but they are not on the first level of procurement, situation that reflects the limited capacity that the aerospace industry has in the state (Conacyt, 2014, p. 59). Most companies are certified by Nadcap and As9100, and over $90 \%$ of all manufacturing companies with 250 employees or more, are certified under Iso 13485 and Iso 9000 standards (Conacyt, 2014).

Economic development in this state has been articulated based on a cluster policy, as it is considered as a place of convergence of strategic figures in the processes of research, technological development and innovation. Among the strategic clusters we have the aerospace sector, in addition to the automotive, medical and dental devices, information technology, electronics, logistics, agribusiness and wine (Conacyt, 2014, p. 34).

Although the service sector ranks first in economic activities of the state, the manufacturing industry is also important because of its impact on employment, foreign direct investment and education. The natural, material and human resources that the state possesses, have made possible a successful venture into sectors such as electronics, aerospace, food industry, biotechnology, among others (Conacyt, 2014).

The authorities of Baja California consider that their proximity to the technology hub of San Diego, California, contributes to capitalize higher value-added activities and new business options so individual strategic sectors can be integrated into global value chains. The specialty niches that have been defined for the aerospace sector are: vendor certifications, advanced technical capabilities and development of advanced materials (Conacyt, 2014).

The weaknesses that the state shows in this sector is the fragile link between academy and business, the inadequate response of the sector to respond to global technological trends, a weak supply chain and lack of integration of national procurement, human capital shortages experienced in conventional manufacturing processes, small amount of activity in the government-industry-academy plans and an incipient incorporation of cutting-edge technology to manufacturing processes (Conacyt, 2014 , p. 60). The lack of integration of national procurement, although it is a weakness in the current context, it is also seen as an opportunity to encourage the development of local supply and development within the sector, this work is a contribution about the situation of the local integration.

Despite the lack of studies in the state of Baja California regarding the situation of Mexican companies in the aerospace sector, there are valuable analysis such as Hualde 
and Carrillo highlighting the importance played by human capital in this industry and raise the importance of training, linking and development of educational institutions to help meet the demands of the industry and create competitive human resources. The study focused on analyzing the production characteristics and the labor and professional competition demanded by this industry in the state, which eventually generalizes to other regions (Hualde \& Carrillo 2007).

It is noted that neither in the official information of the state, nor in studies performed on the sector, Mexican companies located in this region have been studied, although the need to strengthen the ecosystem of suppliers for the aerospace industry is recognized. Furthermore, it considers the need for a network of specialized technological services as an opportunity niche and the need to promote the development of the supply chain in the aerospace industry, taking advantage of the many manufacturing companies that comprise the state (Conacyt, 2014).

\section{Methodological Strategy}

Data for this work is part of the doctoral thesis "Mexican companies in the value chain of the aeronautics industry" where Mexican companies were analyzed in several states. This chapter presents some of the results of the empirical research as a result of an electronic questionnaire and interviews with Mexican companies in the aeronautics industry.

The lack of information meant that the information had to be generated from scratch: a general directory of all the companies that have been registered in the country was built, compiling information provided by official bodies to consolidate a reliable directory, where 259 companies were identified. From then on we proceeded to identify Mexican companies.

In the case of Baja California, 6 companies, of $100 \%$ Mexican origin, were located, although there was only access to 4 of them, which constituted the sample for this analysis. Although it is a small number, based on the complexity and characteristics of the sector and the large number of transnational corporations in the state, it is interesting to analyze these local businesses.

To analyze the information, a database with the questionnaire responses was built, and with support from the spss statistical program, labels were created so that the treatment of the data was homogeneous. The completed questionnaires were obtained through e-mails, telephone calls and visits to the companies, these interactions also served for in-depth interviews with company personnel. In terms of percentages, in Baja California, $67 \%$ of the located Mexican companies were covered, of which $50 \%$ are large and medium and $50 \%$ are small. 


\section{Characteristics and Possibilities of Insertion of Mexican Aeronautics Companies in Baja California}

Six companies of Mexican capital were identified in Baja California, although there was access to only four of them, which represents $26 \%$ of all Mexican companies identified in the country by 2014. The first question of this analysis refers to, what are the characteristics of Mexican aerospace companies in the state of Baja California? These are companies that come from the machined sector, three of them continue to operate in their sector of origin in addition to aeronautics, and one of them is totally dedicated to aeronautics.

The way these companies started operations in aeronautics was mainly because the owner or an employee previously worked in an aeronautics company and the second reason was by a strategy of diversification of activities, it can be observed that linking with other businesses plays an important role in the inclusion of local businesses, although there are also companies that perform proactive actions to integrate hightech sectors like this one.

In a sector with such particular characteristics as the aeronautical, joining in is not enough, the central task is to remain in it, to achieve this, Baja Californian companies have resorted to strategies such as cost and flexibility, i.e., have a competitive price for the customer and be flexible to the demands and requirements in terms of use of materials and delivery times. Another strategy is human resources and differentiation, and in some cases customer proximity, because for some multinational companies it is essential to have suppliers within close geographical distance to streamline the production process and have a quick response to quality problems or supply of parts.

The four identified companies are certified by the basic rule for aeronautics providers, As9100. The 9100 Series is a model for systems of quality management in the aeronautics sector based on the standard Iso 9001: 2000, the general enforcement is in charge of the International Aerospace Quality Group (IAQG) and whose responsible entity is the Society of Automotive Engineers (SAE). The As9100 certification emphasizes the quality, safety and technology of all stages of the supply chain and is applicable in all areas, both civilian and military. Ability to obtain this certification involves a series of requirements and carries high economic costs, therefore, the fact that Mexican firms are certified, shows that these are solid companies and could have a valuable path in the sector.

In addition to As9100, an enterprise has the International Traffic in Arms Regulations (ITAR $)^{4}$ standard, which is a license, that includes a set of government regulations of the United States which controls the import and export of defense items and services and covers the aeronautics sector (Trade, 2014), suggesting that it's a company with clients in the area of defense in the United States. As noted, this companies have made investments to enter the sector, the most important and fundamental part is the basic certification, because it's a sector that is governed by regulations and certifications that are the foundation for any level provider.

\footnotetext{
${ }^{4}$ ITAR regulations dictate that any information and material related to military defense and related technologies can only be shared with people and companies in the us unless it authorized by the United States Munition List (USML) (Trade, 2014).
} 
On the other hand, it is important to note that no company makes expenditures on R\&D, reflecting that they perform activities of low added value, we will later see the type of products they produce and the links of the value chain to which they are linked.

With regards to government support, such as funds or some sort of stimulus, no Mexican company in the aeronautics sector in Baja California has received this type of support, despite being a state which has been defined as one of the priority sectors for the near future and has two cluster associations to gain momentum, local businesses have not had access to financial support or key information that enables them to improve their position within the sector.

As for links with external sources, no dynamism or strategies to cooperate or ally with external agents have been shown, only two companies have been linked to private laboratories, mainly for technical assistance, they do not perform collaborative practices for new developments or advice on the use of new materials or treatment of parts, and only one company has approached the council on science and technology and the state's Secretariat of Economy for the same purpose.

In the case of universities, only one company has been linked, but not for production process related activities, but to access social service staff. Similarly, only one company has a relationship with intermediate associations, but it has been for attendance at events or fairs. Only one company has approach Promexico to access information. No company has had contact with public laboratories, research centers or the Conacyt. This shows not only the weak bonding capacity of enterprises, but also the lack of tools to help them access key information and strategic actors for development within the sector.

Companies have paid external advisors to meet legal requirements, certifications and environmental and security issues, which provide elements about their problems and is an opportunity for the state's government to support them in these issues.

The second question is, to which links in the global production chain are the Baja California Mexican companies attached? The companies replied that their main customers are in the highest links of the value chain, they are suppliers for oEms, Tier 1 and Tier 2.

This means they have gained access to companies that perform the final assembly of airplanes or helicopters, manufacture of parts and components, design and develop new aircraft models, and the sale to the end customer. Tier 1 companies are second in importance (after OEMs) and are involved in the assembly, manufacturing products with high added value and integration of major subsystems, and Tier 2 companies specialize in the assembly of various subassemblies and sections for join aerostructures, avionics, engines, aircraft interiors and landing gear.

It is necessary to analyze what activities or parts they manufacture, since being a supplier of the highest levels of the value chain does not guarantee their permanence in the sector. This finding is consistent with the empirical evidence, which suggests that the most dynamic region by its interaction with oems is the north of the country, which could indicate that the Mexican companies in this region are the ones conducting activities with higher added value.

Although this finding seems contradictory to the study of Gomis \& Carrillo (2016), which concluded that the terms of the global value chain (GVC), the bulk of the activity seems to be at lower levels or links of the production process, it suggests that companies located in Baja California mostly realize procurement to support companies that produce parts and components for other companies outside the country, which in turn produces systems and subsystems. These authors also found that most companies in the region $(80 \%)$ are Tier 3 and 4 . It means that their 
activity is geared towards providing manufacturing parts and components to other companies that produce systems and subsystems (Gomis \& Carrillo, 2016). This suggests that local businesses are suppliers of companies located outside the country and not multinationals established in Baja California, this idea makes sense because $90 \%$ of the production of the analyzed companies go abroad, and only $10 \%$ stays in the domestic market.

The United States is the country where they export the most, which is a great opportunity for businesses by geographic proximity and because it's the country with higher income and a world leader in this industry, only one company has customers in Europe, Asia and the Middle East. Although it is one of the most dynamic states in terms of investment in this sector, it is noted that the linkage with foreign companies is very low at the level of local companies, because, as Gomis \& Carrillo proposed, there is little or no obligation on Multinational Enterprises (MNEs) to establish contracts with Mexican companies, which is compounded by the fact that established MNEs don't seem to have a special interest in linking with local businesses (Gomis \& Carrillo, 2016).

The third question of this work is what activities do the Baja California enterprises carry out and what are the opportunities to continue diversifying activities? The products fabricated by Mexican Baja California companies are radio frequency modules, parts for electrical support, insulating parts and rotors, stators and armor, which coincides with the productive vocation of the region that has historically been the electronics and machining industry, with processes such as: precision machining, electrical systems, and processes shaping metal plates. Even the stablished multinational companies manufacture electronic and electrical equipment for aircraft and engine parts, which shows that they are taking advantage of the region's capabilities of human capital and resources.

Of the four Mexican companies, three handle a single product for aeronautics and one of them handles more than twenty, this reflects that only one company maintains a good level of integration to the sector, because when a company manufactures more products, it shows more experience and greater opportunities to continue diversifying, and therefore it is not vulnerable with having to leave the sector if the client for that unique product discontinues its demand.

As noted, the products they fabricate are basically manufacture, only a relatively low proportion carries out activities with higher added value such as engineering and design with $17.3 \%$ and MRO with $10.7 \%$, which adds to the idea that investment in this industry seeks to exploit the region's experience in manufacturing (Gomis \& Carrillo, 2016). The interviewees also expressed that the activities they perform are maquila, and their work difference with other sectors are the very strict quality and certifications required for production. Furthermore, they express that sometimes the pieces are not as complex as the management part, which is the need to understand the particularities of the sector and the investment to win a contract.

Although it seems they make low value-added activities, one cannot talk about simple activities in this sector, because even the manufacturing or assembly activities must comply with the certifications demanded by the client and the sector; which, as expressed by some employers, demands high volumes of investment, high dependence on innovation and R\&D. 


\section{Discussion}

The aeronautical sector is strategic for its high technology content and for its enormous prestige at the international level. This implies that all activities require as 9100 certification, regardless of their complexity and place within the productive process where they are located. Covering the certification requirements is the minimum necessary condition that companies require in order to be able to respond adequately to the needs of the aeronautics industry in productive, quality and safety terms.

The acquisition of certifications generally comes hand in hand with the productive experience of companies, accumulated learning, diversification of their products and processes, and the skills to connect with new customers. In particular, technological and productive capacities are an important factor in positioning and increasing opportunities for insertion and subsequent upgrading.

The insertion of Mexican companies into the value chain of the aeronautics sector has been conditioned byseveral factors and few have been successfullyintegrated (Hernández, 2015). In this sense, basic certification is only the first step for companies to be part of the industry; but the real challenge is to find niches of opportunity and negotiation capacity to achieve a productive contract with the client, which demands entrepreneurial, legal and economic skills. In other words, it is not enough to demonstrate productive capabilities, but sMEs need to understand the dynamics of the sector, production cycles, support large investments and even adopt values such as cleanliness, confidence and security. In this sense, the entry barriers to the sector are high. Carrincazeaux \& Frigant (2007) mention that great secrecy, a high level of vertical integration and a very strong hierarchy in the production chain have historically characterized the aerospace industry. Around the big producers there are several hundred small companies that operate in a process of strong control through rigid specifications, so once a supplier is part of the chain is very difficult to leave, because it is not easy to find suppliers that meet the requirements that are demanded.

Nonetheless, some SME companies were able to enter the Baja California aerospace sector thanks to access to certain supports (financing, technical assistance for certification, linking with potential customers through trade shows and business meetings). Although the number of related companies is very low, the results can be classified as positive and with potential, taking into account the high requirements of the sector previously mentioned.

The Baja California aerospace industry has diverse production processes that are a source of opportunities for local businesses. For example, components for machinery, harnesses and cables, components for landing systems, plastics injection, heat exchangers, precision equipment, repair of supporting surfaces, audio and video systems, electronic components and interiors (Producen, 2006). Three central activities were identified recently in the clusters of Tijuana and Mexicali: harnesses and accessories of electrical cables; propellers, rotors and engine parts and components; and electrical and auxiliary airborne components (Gomis \& Carrillo, 2016). More than $80 \%$ of the aerospace plants in Baja California were at Tier 3 and Tier 4 levels, and several suppliers are of basic inputs and processing services (Gomis \& Carrillo, 2016). In other words, given the level within the value chain in which aerospace plants are located in the State of Baja California, it is possible to integrate more suppliers and eventually scale to better positions. 
The companies we studied were able to link with both oEm firms and companies located in Tier 1, 2 and 3. And do not necessarily integrate their production and processes to plants located in Baja California but some cases export directly to companies in the United States. In addition, we find that SMEs can be suppliers of clients at different levels; since there are parts, for example, that require both an OEM in the assembly process of the aircraft and a Tier 1 in the wing production process. Certification is the guarantee to serve several levels of the value chain.

Despite being integrated into the value chain, the sustained growth of these local companies is determined by the upgrading, that is, the progress in the links of the value chain through more complex activities, with greater added value and forming part of a more robust business environment. This upgrading process is accompanied by both appropriations of knowledge and access to new demands. However, as is well known, upgrading is not automatic and depends a lot on new investments in specialized certifications (the use of new materials or processes implies new certifications that guarantee that the supplier knows and handles them properly). In addition to the above, it is added that the return on investment, insofar as the activity is more complex, is greater but it is in the longer term. Therefore, the lack of financial resources and opportunities to access credits and financing modalities to access new niches become the most important limitation for upgrade. Therefore, some companies interviewed told us that they preferred not to diversify activities due to all the implications that this demands (modernize the plant, purchase of machinery, certifications, etc.). In other words, they decided not to upgrade.

Our study shows that not all obstacles faced by smes in the aerospace sector are productive (quality of products, capacity to satisfy customer requirements, etc.), but in many cases they are more related to the management of the complexity of the sector (certifications, economic resources, investment in physical capital or negotiation skills with clients).

The development of the aeronautical sector is not homogeneous in Mexican regions. The productive trajectories, the resources destined and the political context mark the differences. The regions in that sense have a political character, since the state governments are without a doubt the main agents of promotion and development of the industry. In this sense, changes of administration, regardless of the political party that governs, may be relevant to understand the continuity, progress and even deterioration of the sector. Although the role of federal agencies such as Conacyt, Secretaría de Economía, or ProMéxico is proactive and relevant, sometimes there's not guarantee of continuity in programs focused on supporting companies by what has been mentioned above.

In the case of the aeronautics industry in Baja California, the region does have an impact on the level of insertion. The companies in this state, and in northern Mexico, are the best positioned and the most benefited of programs and public policies have had (Nuevo León, Baja California and Chihuahua), with the exception of the case of Querétaro. Although the programs have allowed smes to enter the aerospace value chain (under match-making schemes with clients), the impact on the development of endogenous capacities or the closing of productive and technological gaps has moved very slowly; and the articulation of public (federal) research centers with Mexican companies is still very limited.

If we take into account that the strategic decisions that multinational corporations take to relocate their productive, research and design or after-sales activities depend 
not only on comparative advantages, but increasingly depend on federal policies and programs, and mainly state, the challenges that the public policies are facing are clear to get scaled SME companies linked to the aeronautical sector.

The fact that Mexican smes in Baja California carry out low value-added activities and have incipient technological capabilities suggests that there is a long way to go in terms of public policies that support not only the certification process but also the creation of credit conditions and financing of long breath. Given the importance of the financial hurdle and the low level of companies in the value chain, it requires the creation of public policy mechanisms to take advantage of the experience accumulated in the Baja California region that seeks upgrading.

The OECD has raised the importance of identifying local strengths to align policy actions and increase critical mass to develop a vision and implement a strategy for the regions. In Mexico, comprehensive programs are needed to support companies with potential capacities to integrate into this sector; it is also necessary to generate more information about companies so that you are able to access mechanisms that allow them to be inserted. But above all, it is necessary to direct policies towards the companies already integrated so that they manage to upgrade. In summary, it is recommended to strengthen financing programs focused on non-integrated sMEs as well as those already linked. Create support programs according to size, as within sMEs are companies of very different levels of employment, sales and skills. And develop interfaces that seek more dynamic relationships between companies and the environment, through links with key public and private organizations, intermediary organizations, research centers and universities. The trajectory and vast experience of Mexican SMEs in supplying sub-systems and parts in the aeronautical sector in different regions of the country offers not only a potential market in the area of repair and maintenance, but also for other dynamic sectors (metal mechanic, automotive, textile, electronics). This characteristic of some smes (potential sectoral diversification) would have to continue studying it and consequently to promote adequate public policies.

\section{Conclusion}

The aeronautics sector in Mexico has gained great importance due to the constant establishment of companies throughout several decades. Although, this companies started with simple assembly and manufacturing processes seeking to export to the United States, nowadays they count with a more complex structure, distinguished by the different activities within the value chain (assembly, manufacturing, design, maintenance, research, and development — MRO). This complexity has been associated to the development of multiple technological, organizational, and human capabilities from companies, as the institutional environment, mainly the educational one. One of the main factors associated to the development of these capabilities, are the certifications that oEM companies require from all their suppliers in their different levels. Mexican companies, all of them which have a reduced employment rate, are not alienated from these practices. Just like the other multinational companies, their people and their processes have to get certified. This feature of the aeronautics sector is fundamental to understand not only the challenges that the smes (and all the associated companies) have to reach in the industry, but also the capabilities achieved by them. 
Although the industry is in a stage of great dynamism and strong support by the federal and state governments, the level within the global value chain is still in low level positions. With few exceptions of smes (like Bombardier, Cesna and others), and Tier 1 companies (like Honeywell), most of the companies in Mexico are located in levels 2 and 3 of the chain.

Our study shows that the aeronautic sector in Baja California consists mostly of foreign companies ranked in the lowest levels of the chain. Very few companies are Mexican suppliers. However, despite the great limitations that these aeronautic smes have, they manage to provide components to oem firms, as well as to Tier 1 and Tier 2 companies. The development of capacities and certifications they have achieved allows to raise the idea that the Mexican companies are only in the lowest level of the value chain. Unfortunately, there are very few national companies in this sector, but if a growth trend remains, we will see more integration in the near future, and eventually a greater economic impact and technological transfer in the regions where these companies are settled.

\section{References}

AeroStrategy. (2009). Implications for Canada's Aerospace Industry a Discussion Paper. Canada. Amighini, A., Rabellotti, R., Pavia, U. \& Scalera, V. (2013). Technology-Driven FDI : A Survey of the Literature (Papers in Innovation Studies 2013/17). Lund University, Center for Innovation, Research and Competences in the Learning Economy, Sweden.

Casalet, M. (2013). Actores y redes públicas y privadas en el desarrollo del sector aeroespacial internacional y nacional: el clúster de Querétraro, una oportunidad regional. In M. Caselet (Ed.), La industria aeroespacial: complejidad productiva e institucional (pp. 93-134). Mexico: Flacso.

Carrincazeaux, C. \& Frigant, V. (2007). The Internationalization of the French Aerospace Industry: To What Extent Were the 1990s a Break With the Past? Competition and Change, 11(3), 261-285.

Consejo Nacional de Ciencia y Tecnología (Conacyt). (2014). Agenda de Innovación de Baja California. Mexico: Author.

Eliasson, G. (2010). Advanced Public Procurement as Industrial Policy, The Aircraft Industry as a Technical University. New York, United States of America: Springer Sciencie, Business Media.

Elola, A., Valdaliso, J. M. \& López, S. (2013). The Competitive Position of the Basque Aeroespatial Cluster in Global Value Chains: A Historical Analysis. European Planning Studies, 21(7), 1029-1045. doi:10.1080/09654313.2013.733851

Federación Mexicana de la Industria Aeroespacial. (2012). Programa Estratégico de la Industria Aeroespacial. Mexico: Secretaría de Economía.

Gomis, R. \& Carrillo, J. (2016). The Role of Multinational Enterprises in the Aerospace Industry Cluster in Mexico: The case of Baja California. Competition E Change, 20(5), 337-352.

Hernández, J. (2010). Mecanismos de aprendizaje en la transferencia de conocimientos del modelo 400 y global express: el caso de Bombardier Aeroespace, Querétaro (Tesis). Mexico: Universidad Autónoma Metropolitana-Xochimilco. 
Hernández, J. (2015). Las empresas mexicanas en la cadena de valor de la industria aeronáutica (Tesis doctoral). Mexico: Flacso.

Hualde, A. \& Carrillo, J. (2007). La industria aeroespacial en Baja California: Características productivas y competencias laborales y profesionales. Mexico: Colegio de la Frontera Norte.

Jordaan, J. A. (2012). Agglomeration and the location choice of foreign direct investment: new evidence from manufacturing FDI in Mexico. Estudios Económicos, 27(I), 61-97.

López, S. M., Elola, A., Valdaliso, M. M. \& Aranguren, M. J. (2012). El clúster de la industria aeronáutica y espacial del País Vasco: orígenes, evolución y trayectoria competitiva. España: Euko Ikaskunta, Instituto Vasco de Competitividad, Fundación Deusto.

Mani, S. (2010). The Flight From Defence to Civilian Space: Evolution of the Sectoral System of Innovation of India's Aerospace Industry. ERIA Supporting Study Project, India.

Morissette, L., Barré, P., Lévesque, C. \& Solar-Pelletier, L. (2013). El desarrollo de ventajas competitivas institucionales: el caso de la industria aeroespacial en Montreal. In La industria aeroespacial: complejidad productiva e institucional (pp. 21-48). Mexico: Flacso.

Niosi, J. \& Zhegu, M. (2005). Aerospace Clusters: Local or Global Knowledge Spillovers? Industry E् Innovation, 12(1), 5-29.

Organization for Economic Co-operation and Development (OECD). (2011). Attractiveness for Innovation: Location Factors for International Development. New Directions for Youth Development (Vol. 2013). Paris: Author. doi:10.1002/yd.20075

Office of Aerospace and Automotive Industries International Trade Administration. (March, 2007). Analysis of the U.S. Aerospace Industry. United States of America: Author.

Producen. (2006). México y la industria aeronáutica global. Una publicación para entender, obtener información y generar estrategia. Mexico: Producen-Centro de Inteligencia Estratégica.

Secretaría de Economía. (2012). Industria Aeronáutica en México. Mexico: Author.

Trade, C. F. (2014). Licencia ITAR. Mexico: Author.

Juana Hernández Chavarria

Mexican. PhD in Research in Social Sciences by Flacso-Mexico. Graduated in Administration and Master in Economy and Management of Innovation by the Universidad Autónoma Metropolitana-Xochimilco. She performs a postdoctoral degree in the Faculty of Economics of the Universidad Nacional Autónoma de México and is a member of the Thematic Network Convergence sponsored by the Conacyt and candidate in the National System of Investigators. Research lines: technological and organizational capacities, technological innovation and new productive modalities in emerging sectors.

Jorge Carrillo

Mexican. He has been a professor-researcher at El Colegio de la Frontera since its founding in 1982. He holds a PhD in Sociology from El Colegio de México. He has the 
highest category within the SNI and is a member of editorial committees of important magazines in Mexico and abroad. He actively participates in boards of directors of international research networks. In 2015 he received the State Award of Science and Technology of Baja California. Among his recent publications: Carrillo, J. H. \& Micheli, J. (2017). Huawei y Foxconn: casos pioneros de la nueva internacionalización y expansión regional de China en México. Estudios Sociales, Revista de Alimentación Contemporánea y Desarrollo Regional, 27(50). 